\title{
A Case Study of Pyramid Scheme Finance Flow Network Based on Social Network Analysis
}

\author{
Pihu Feng ${ }^{1}\left(\mathbb{D}\right.$, Duoyong Sun ${ }^{1}$ and Zaiwu Gong ${ }^{2, *}$ \\ 1 College of Systems Engineering, National University of Defense Technology, Changsha 410072, China \\ 2 School of Management Science and Engineering, Nanjing University of Information Science and Technology, \\ Nanjing 210044, China \\ * Correspondence: zwgong26@163.com
}

Received: 25 June 2019; Accepted: 7 August 2019; Published: 12 August 2019

\begin{abstract}
Background: The pyramid scheme has caused a large-scale plunder of finances due to the unsustainability of its operating model, which seriously jeopardizes economic development and seriously affects social stability. In various types of networks, the finance flow network plays an extremely important role in the pyramid scheme organization. Through the study of the finance network, the operational nature of pyramid scheme organizations can be effectively explored, and the understanding of pyramid scheme organizations can be deepened to provide a basis for dealing with them. (2) Methods: This paper uses the motifs analysis and exponential random graph model in social network analysis to study the micro-structure and the network construction process of the "5.03" pyramid scheme finance flow network in Hunan, China. (3) Results: The finance flow network is sparse, the microstructure shows a typical pyramid structure; finance flows within the community and eventually flows to the most critical personnel, there is no finance relationship between different communities, and there are few finance relationships between pyramid salesmen of the same level. The inductees are in a key position in the network, which may explain why they are transferred to prosecution.
\end{abstract}

Keywords: finance flow network; pyramid scheme; social network; motif analysis; exponential random graph models

\section{Introduction}

A pyramid scheme generally refers to the business model that recruits members via a promise of payments or services for enrolling others into the scheme, rather than supplying investments or sales of products. There are some differences in the concept of pyramid selling between China and other countries. In accordance with the Regulations on Prohibiting Pyramid Marketing promulgated by the Chinese Government in 2005, a pyramid scheme refers to the behavior where organizers obtain illegal benefits, disrupt economic order, and affect social stability by calculating and paying remuneration for the number of personnel or sales performance directly or indirectly developed by the developer, or requiring the developer to qualify for membership on the condition of paying a certain fee. From the above definition, it can be seen that the definition of the pyramid scheme in China is more general than the internationally accepted definition of the pyramid scheme, which includes legitimate multi-level direct selling activities abroad. In fact, the operation mode of the " 5.03 " pyramid scheme organization in this paper conforms to the above two definitions.

Recently, with the development of social economy, the spread of pyramid schemes around the world has gradually accelerated and is becoming more and more destructive, endangering the economy of many countries and bringing great harm to the social order, some pyramid scheme organizations even showing violent characteristics [1-4]. With the development of Internet technology, network 
marketing has become more popular and more destructive [1,5]. Due to the great harm of the pyramid schemes, many countries have identified pyramid schemes as illegal. The development of the pyramid scheme is unsustainable because the pyramid scheme itself does not produce any valuable products or services, and its development depends on the continuous development of the downline [6]. A country's economy has a certain size and cannot support the long-term development of a pyramid scheme. Therefore, in this sense, the pyramid scheme itself is not sustainable. According to a consumer supervision agency from Australia, 99.0 to $99.9 \%$ of people in the pyramid scheme actually did not make any gains and lost a lot of money [7].

At present, there are many studies on pyramid scheme organizations from different angles. Bosley and Mckaege argued that the degree of economic contraction in the county is positively correlated with the degree of participation in pyramid schemes [8]. Walsh believes that the products sold by a pyramid scheme are seriously inconsistent with the actual value, and even that "no real products can be sold" [9]. Schiffauer believes that pyramid schemes only benefit a small number of participants and lead to serious social problems [10]. The Australian Competition and Consumer Commission believe that pyramid schemes are different from false advertising, misleading price statements, and other fraudulent marketing practices, and that making money from the development downline is the main target of pyramid schemes [7]. In addition, some researchers believe that the organizational structure of the pyramid scheme is a multi-fork tree structure, its mode of operation is a strict single-line connection, and that the entire organization has a strict subordinate relationship $[6,8,11]$.

These studies clearly illustrate the connotations and characteristics of pyramid schemes and deepen the understanding of the pyramid scheme. However, most of these studies involve qualitative analysis, a lack of quantitative analysis, and especially lack of research on the structure of the pyramid scheme.

Social Network Analysis (SNA) is a structural analysis method for processing relational data, which is used to study the relationship between actors and their roles in shaping individual and group behavior [12,13] and is able to discover the relationships between members and the structural characteristics of the system hidden under complex social systems [14-16]. Motifs analysis and exponential random graph model analysis are classical analysis methods in social network analysis, which are used to analyze the network microstructure and the endogenous construction process of the network. The motif is a frequent subgraph of the network in the isomorphic sense. It is suitable for analyzing the microscopic structure of the network and finding the key microscopic features of the network structure by comparing with the random graph $[17,18]$. The exponential random graph model focuses on the construction process of the network and is suitable for mining the interactions in the network $[19,20]$. In this paper, motifs analysis is used to mine the micro-flow characteristics of the finance flow network, especially the characteristics of financial flows associated with indicted persons. The exponential random graph model is used to study the formation mechanism of the financial flow network, especially the characteristics of financial flows between communities and between indicted persons.

Social network analysis is also commonly used in financial research. Carlos León et al. studied the interbank financial network by social network analysis and gave a way to identify important people [21]. Massimiliano Affinito used the centrality theory of social network analysis to study the impact of the Global Financial Crisis (GFC) on interbank market connectivity and argued that the use of social network methods to analyze the financial network can effectively explore the important characteristics of these organizational networks [22].

In all types of pyramid scheme relationships, financial relations have a very important position. Considering that finance flow is the ultimate pursuit of pyramid scheme organization, researching financial relationships will be very helpful to discover the essential characteristics. In this study, we use the motif analysis and exponential random graph models to study the pyramid scheme finance flow network to reveal the typical microstructure and formation mechanism of the finance flow network, thus broadening comprehension of the pyramid scheme. 


\section{Materials and Methods}

\subsection{The "5.03" Finance Flow Network}

Since its entry into China, the pyramid scheme has developed rapidly due to its inherent enthusiasm for money and success and the eagerness of ordinary Chinese for resources. The pyramid scheme presents a clustering development model, which can be divided into the North Pyramid Scheme and the South Pyramid Scheme, according to the origin and operation characteristics. The North Pyramid Scheme originated in Northeast China, and the typical case is the Tiens Sunshine System. This type of pyramid scheme is characterized by no real product sales, centralized accommodation, and unified classes, hard living conditions, and strict restrictions on personal freedom. After 2008, the South Pyramid Scheme, such as Project 1040, emerged and gradually became the mainstream form of the pyramid scheme. The South Pyramid Scheme originated in Guangxi, China. It is usually packaged in the form of "capital operation" with much confusion and deception. It generally does not restrict personal freedom. It relies on "brainwashing" and uses windfall profits as bait. Brainwashing, which fits the group fanaticism, plays a vital role in the pyramid scheme organization. It describes a successful life from four dimensions: Action goal, means, technology, and external norms. By means of isolation, authority, and rules, pyramid scheme organizations carry out an all-round team ideological transformation from five aspects: Self-transcendence, change of mental model, instilling common vision, group learning, and systematic thinking. When every member believes that the cause can succeed, they will abide by the rules of the business and act consciously.

A pyramid scheme itself does not create profits, it relies on the continuous development of new participants to survive. Once there are no new participants, there will inevitably be financial breakage, and thus will form a bubble economy. Relying on fascination and the people's enthusiasm for money, the pyramid scheme has become more and more fierce in China, which has seriously affected social stability and economic development. In 2006, the Chinese government banned 29,900 pyramid schemes and transferred 690 people. In 2019, Nanchang, a normal medium-sized city in China, banned 10,809 pyramid schemes and transferred 128 people. In terms of the amount involved, the Shanxinhui pyramid scheme organization headquartered in Hunan, China, involved 104.6 billion yuan.

The " 5.03 " pyramid scheme organization headquartered in Hunan operated in a typical South Pyramid Scheme mode and was named after being dismissed on 3 May. When it was detected, the "5.03" pyramid scheme organization had spread to many provinces across the country, involving more than 100 million yuan [23]. It operates in a "five-level and three-stage" mode, with top-down management. It "brainwashes" its members by fabricating various visions and formulates rules such as "20 Articles of Life Elite" for personnel management.

In the organization, participants must spend 3800 yuan to 69,800 yuan to purchase 1-21 virtual products, so as to qualify for membership. The " 5.03 " pyramid scheme organization divides the members into 5 levels from the bottom up, according to the virtual product share in the network. These 5 levels are E-level (internship salesman, cumulative share of 1-2), D-level (business leader, cumulative share of 3-9), C-level (business director, cumulative share of 10-64), B-level (business manager, cumulative share of 65-599), and A-level (senior salesman, cumulative share of more than 600). The promotion of members in the organization can be divided into three stages: The first stage is from internship salesman to business leader and then to business director; the second stage is from business director to business manager; and the third stage is from business manager to senior salesman. After the "5.03" pyramid scheme organization was detected, 16 persons were prosecuted (Table 1). 
Table 1. List of participants who were prosecuted.

\begin{tabular}{cccccc}
\hline Node Number & Level & Node Number & Level & Node Number & Level \\
\hline 2 & A2 & 25 & A1 & 89 & A1 \\
3 & A1 & 37 & A1 & 135 & A1 \\
5 & A1 & 41 & A1 & 136 & A1 \\
7 & A1 & 44 & A1 & 137 & A1 \\
10 & A1 & 59 & A1 & & \\
17 & A1 & 75 & A1 & & \\
\hline
\end{tabular}

Note: A1 and A2 represent different levels, and A2 has higher levels. In this paper, the No. 2 node (A2 level) represents the key players in the network.

We used manual methods to process relevant data and obtained 163 financial relationship data between 177 organizational members who come from 4 communities and are divided into 5 levels. Since the finance flow is directional and there is a difference in quantity, the finance flow network is directed and weighted. The weight value of the finance flow represents the number of shares and the actual amount of finance flow is the weight value $\times 3800$ yuan.

\subsection{Descriptive Statistical Analysis}

There are a lot of effective measures in social network analysis that can be used to describe the finance flow network from multiple perspectives. Some typical measures are shown in Table 2.

Table 2. Social network analysis measures.

\begin{tabular}{cl}
\hline Measure & \multicolumn{1}{c}{ Definition } \\
\hline Density & $\begin{array}{l}\text { The density is the ratio of the actual number of connections between network } \\
\text { members to the number of connections that may exist in the network [24]. It can } \\
\text { represent the tightness of connections between nodes. }\end{array}$ \\
\hline Average Distance & $\begin{array}{l}\text { The average distance is the ratio of the sum of the distances between all nodes in the } \\
\text { network to the number of node pairs that are linked in the network [25]. It is used to } \\
\text { describe the extent of the network hierarchy. }\end{array}$ \\
\hline Connectivity & $\begin{array}{l}\text { The connectivity refers to the degree of reachability between any node in the network } \\
\text { [26]. It is used to measure the flexibility of the network. }\end{array}$ \\
\hline Transitivity & $\begin{array}{l}\text { The transitivity refers to the ratio of the number of observed triangles in the network } \\
\text { to the number of triangles in theory [27]. It is used to describe the degree of intimacy } \\
\text { of regional members. }\end{array}$ \\
\hline Degree Centralization & $\begin{array}{l}\text { The degree centralization of a network is the variation in the degrees of vertices } \\
\text { divided by the maximum degree, which is possible in the network of the same size } \\
\text { [26]. It is used to describe the closeness of the graph around a certain core node. }\end{array}$ \\
\hline
\end{tabular}

\subsection{Motifs Analysis}

Unlike the above global analysis, the motif can analyze the network from the micro-level. As a typical, local, and functionalized frequent subgraph, motifs can represent local information of the network and have strong statistical significance [28,29].

At present, motif analysis has been widely used in financial research. Squartini et al. applied the motif analysis to study the structure of the world trade network, described the structural characteristics of the 13 three-node motifs, and explained the important role of these motifs in the network [30]. Song Ningning et al. applied the motif analysis to study the structure of the stock trading network and obtained its statistical characteristics [31].

In this paper, motif analysis is used to explore the microstructural features of the interpersonal network to explore the micro-operational model of the finance flow network. 
According to the basic principles of motif analysis given by Milo [28], we have:

$$
Z_{i}=\frac{N_{o b s i}-<N_{\text {randi }}>}{\operatorname{std}\left(\sigma_{\text {randi }}\right)}
$$

where $N_{o b s i}$ is the number of occurrences of the subgraph in the observed network, $<N_{\text {randi }}>$ is the expected number of times the subgraph is in the random network, and $\operatorname{std}\left(\sigma_{\text {randi }}\right)$ is the standard deviation. Two aspects are considered when evaluating the motif: (1) The frequency of the motif appearing in the random network is less than a certain threshold $P$. It is generally considered that the $P$ value should be less than 0.01 . (2) The number of motifs in the observation network is greater than a certain threshold $K$. The $K$ value takes different values due to the consideration of the researchers. It is generally considered that the $K$ value should be greater than 3 . When the above conditions are satisfied, the higher the $Z$ value, the more significant the motif.

\subsection{ERGMs Analysis}

The exponential random graph model (ERGM) is a classic model in social network analysis and is used to explore important factors in the formation of financial flow networks. It can explain the relevant factors of various relationships in the network $[32,33]$ and interpret statistical items in a way similar to the traditional regression model [34,35]. The ERGMs explore the network formation mechanism by explicitly modeling various configurations that may affect network formation.

The general form of ERGMs is:

$$
\operatorname{Pr}(Y=y)=\left(\frac{1}{k}\right) \exp \left\{\sum_{A} \eta_{A} g_{A}(y)\right\}
$$

where $k$ is a constant to ensure that the probability is between 0 and 1 and that the sum of probabilities is $1 . \eta_{A}$ is the coefficient of network configuration statistics and $g_{A}(y)$ represents various network configurations. The essence of the ERGMs is the composition of various configurations when finding the maximum of formula (2).

The essence of the ERGMs is to find the probability of being closest to the observed network $y$ from the set of random networks $Y$ of the same density. The magnitude of this probability depends on various network configurations, which refer to a certain structural pattern that may appear in the network, such as edge, triangle structure, star structure, and so on. The ERGMs set the probability of occurrence of the observed network as the dependent variable and set configurations as independent variables. The task of the ERGMs is to find the combination of the various configurations when (2) reaches the maximum.

In this study, the ERGMs include three attribute configurations: Community, level, and prosecution information. These attribute configurations are used to explore the rules of establishing connections between different levels, different communities, and the prosecuted pyramid scheme personnel. The model also includes infrastructure configurations that characterize other connections in the network, which are used to study the interrelationships among various factors that influence the occurrence of network relationships in the finance flow network.

\section{Results}

\subsection{Visualization and Statistical Analysis of the Finance Flow Network}

Gephi is a classic software for network visualization [36] and was used to visualize the Finance network in this paper. $\mathrm{R}$ has a unique advantage in structural analysis of the network, and the famous statnet package [37] and igraph package [38] were applied to analyze the concepts of the finance flow network. 
To the best of our knowledge, this is currently the most comprehensive visualization of the pyramid scheme finance flow network. As can be seen from Figure 1, the finance flow network presents a strict hierarchical structure, with finances flowing from the bottom (edge) of the network to the center. There is no closed circuit in the finance flow network. The personnel who are transferred to the prosecution are located on the main road of the finance flow. The node No. 2, which is the highest level of the network, is in the center of the network, and all finance flows to the No. 2 node. The finance flow network presents a hierarchical structure. All nodes at the A1 level, except for node 44, are all on the main path of finance flow. Most of the people who were transferred to the prosecution were above the A1 level, except for the 44th node. Moreover, nodes with low levels are at the edge of the network, and nodes with high levels are close to the core of the network, which may indicate that the level is related to the distance from the central node. Through analysis, it can be concluded that the finance flow network has a strict hierarchical relationship, the finance flow is very uniform and concentrated, and the position of personnel being sued is related to their position in the finance flow network.

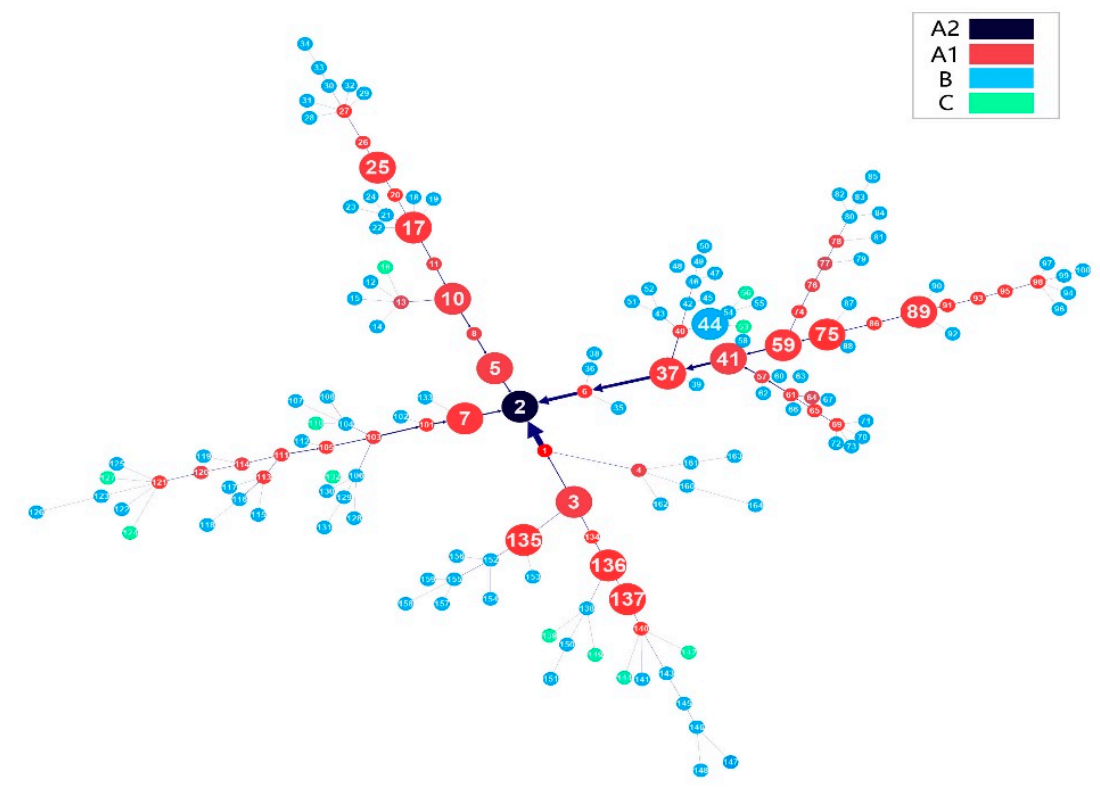

Figure 1. Visualization of the finance flow network. Colors represent different levels in the pyramid scheme. Nodes of larger size are those transferred to the prosecution.

To facilitate the analysis, we constructed a random network with the same number of nodes and density as the finance flow network and explored the statistical characteristics of the finance flow network by comparing the degree distributions of the two networks.

It can be seen from Figure 2 that the indegree distribution and outdegree distribution of the finance flow network are different from the random network. In terms of the indegree, the indegree distribution of the finance flow network is similar to the long tail distribution, that is to say, the finance flow network has some nodes with large indegree, while the node distribution of the random network is relatively linear and there is no node with large indegree. In terms of outdegree, there is also an obvious difference. All the outdegree of the finance flow network is 1, and the outdegree distribution of the random network is also linear. 

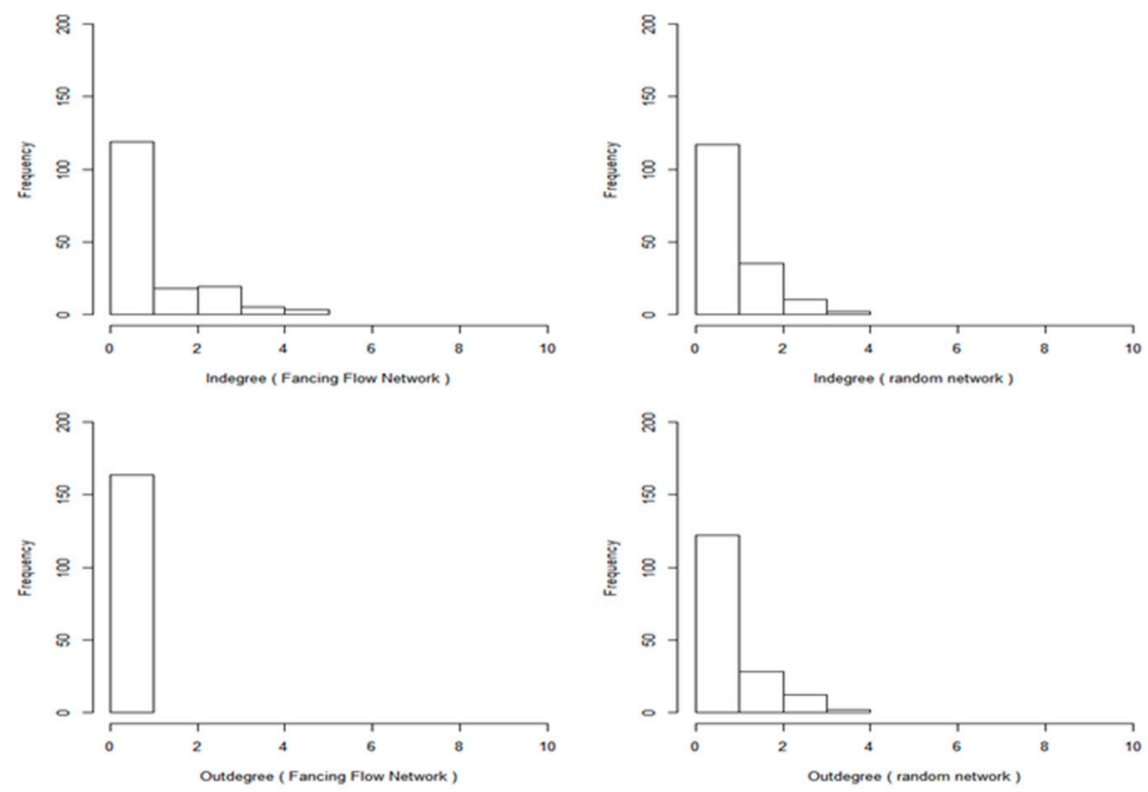

Figure 2. Degree distribution of the finance flow network (left) and the random network with the same density (right).

According to Section 2.2, the relevant indicators are calculated and the results are presented in Table 3.

Table 3. Analysis of the finance flow network.

\begin{tabular}{ccccccccc}
\hline Index & $\begin{array}{c}\text { Number } \\
\text { of Nodes }\end{array}$ & $\begin{array}{c}\text { Isolated } \\
\text { Node }\end{array}$ & $\begin{array}{c}\text { Number of } \\
\text { Relationships }\end{array}$ & Density & $\begin{array}{c}\text { Average } \\
\text { Distance }\end{array}$ & Transitivity & Connectivity & $\begin{array}{c}\text { Degree } \\
\text { Centralization }\end{array}$ \\
\hline Value & 177 & 14 & 163 & 0.006 & 4.468 & 0.039 & 0.964 & 0.006 \\
\hline
\end{tabular}

As shown in Table 3, the density of the finance flow network is 0.006 , indicating that the finance flow network is sparse, which reflects that finance flows are infrequent, and the finance relationship only covers part of the relationship in the organization. The average distance value is 4.468 , which means the network is hierarchical. The connectivity is 0.964 , indicating that the financial flow network has strong connectivity, that the financial relationship covers a wide range, and the flow of finance is very smooth. The transitivity of the finance flow network is 0.039 , which indicates that the " 5.03 " pyramid scheme network finance flow network is concealed and it is not easy to explore the entire outline of the finance flow network. The degree centralization of the finance flow network is 0.006 , indicating that the degree distribution of the entire network is relatively uniform, and there is no complicated financial relationship in the network.

\subsection{Motif Analysis Results}

Currently, there are a variety of methods and software for network motif analysis [39]. For convenience, FANMOD will be used to detect and analyze network motifs [40].

As shown in Table 4, in the 3-node motifs, the No. 12 motif shows the path characteristics of the finance flow network, and that most of the finances are finally delivered to the final person. The motif of No. 2116 shows the characteristics of the finance aggregation transfer. The motif of No. 2184 shows the convergence characteristics of the finances. The motif of No. 218401 phantom shows the role of the indicted person as a finance collector in the finance flow network. The motif of No. 211601 modal shows that the indicted person is at the end of the finance flow, indicating that the prosecutor is the destination of the finances in the "5.03" organization. In the 5-node motifs, it also shows a similar pattern of finance flow to the 3-node motifs and the 4-node motifs, and the role of the indicted persons in the finance flow network was generally the same. It is worth mentioning that the financial flow 
network does not show any closed features and presents a pyramidal (multi-forked tree) structure, which verifies the relevant research conclusions.

Table 4. Motif Analysis Result.

\begin{tabular}{|c|c|c|c|c|c|c|}
\hline ID & Adj. & Frequency & Mean Freq. & Standard Dev. & Z-Score & $p$-Value \\
\hline 12 & & $53.767 \%$ & $53.55 \%$ & 0.0036855 & 0.58812 & 0 \\
\hline 2116 & & $13.628 \%$ & $12.222 \%$ & 0.0043736 & 3.2151 & 0 \\
\hline 2184 & & $9.5764 \%$ & $8.6781 \%$ & 0.0028508 & 3.151 & 0.001 \\
\hline 218401 & & $2.3941 \%$ & $2.1695 \%$ & 0.0007127 & 3.151 & 0.001 \\
\hline 211601 & & $4.7882 \%$ & $4.3219 \%$ & 0.0015432 & 3.0217 & 0.001 \\
\hline 541200 & & $1.434 \%$ & $1.133 \%$ & 0.00084792 & 3.5503 & 0.001 \\
\hline 532744 & & $3.9197 \%$ & $3.0479 \%$ & 0.0025339 & 3.4405 & 0 \\
\hline 532744 & & $1.0516 \%$ & $0.82421 \%$ & 0.00068279 & 3.3306 & 0 \\
\hline 532744 & & $1.2428 \%$ & $0.97106 \%$ & 0.00095356 & 2.8501 & 0 \\
\hline 67632 & & $0.57361 \%$ & $0.14426 \%$ & 0.0017707 & 2.4248 & 0.02 \\
\hline 532520 & & $0.66922 \%$ & $0.24601 \%$ & 0.0017472 & 2.4222 & 0.014 \\
\hline 67088 & & $0.66922 \%$ & $0.24834 \%$ & 0.0017529 & 2.401 & 0.014 \\
\hline 49680 & & $0.86042 \%$ & $0.35767 \%$ & 0.0021958 & 2.2895 & 0.021 \\
\hline 67632 & & $1.7208 \%$ & $0.97039 \%$ & 0.0035135 & 2.1359 & 0.001 \\
\hline 532744 & & $6.501 \%$ & $4.7668 \%$ & 0.0039283 & 4.4144 & 0 \\
\hline 67632 & & $11.95 \%$ & $8.8995 \%$ & 0.0076069 & 4.0105 & 0 \\
\hline 541200 & & $1.912 \%$ & $1.4323 \%$ & 0.0012142 & 3.9514 & 0.001 \\
\hline 66704 & & $13.193 \%$ & $10.192 \%$ & 0.0096039 & 3.1248 & 0.001 \\
\hline
\end{tabular}

Note: Frequency refers to the frequency at which the motif appears in the actual network. The green node in the table indicates that the person was transferred to the prosecution. For the comprehensiveness of the analysis, the table also contains the results of the motif analysis containing the information of the prosecutor and the results without the information (first three columns).

In summary, there are at least three structural meanings of the motifs. First, almost all of the motifs in the table reflect a structure similar to a multi-fork tree. Therefore, the finance flow network can be considered as a multi-fork tree structure and has a strong hierarchy. Second, there is no cross-community link in the finance flow network, which shows that the finance flow network may be the main reason for community establishment and development. Third, the people who were transferred to prosecution acted as a bridge or core role in the finance flow network and played an 
important role in the network. The reason why these people were sued may be related to their position in the finance flow network.

\subsection{Exponential Random Graph Models Analysis Results}

PNET is a classic software for exponential random graph model analysis of networks [41]. It can flexibly set various configurations, and the results are accurate and fast. This section will use PNET to model and analyze the finance flow network. This paper synthetically considers the purely structural effects and attribute effect on network formation. The attributes of nodes contain prosecuted information, community, and personal levels.

As can be seen from Table 5, most of the $t$ values are below 0.1 , and many $t$ values show significations, so the model can be considered a reasonable and convergent model. Specifically, regarding the purely structural effects, the coefficient of reciprocity indicates that there is no two-way finance flow exchange in the finance flow network. The coefficient of 2-in-star $\left(2.039363^{*}\right)$ indicates that the aggregation of finance flow is significant, and the coefficient of 2-path $\left(0.27058^{*}\right)$ indicates that the transferability of finances is obvious. The coefficient of AinS $\left(1.967811^{*}\right)$ indicates that the aggregation of the network is obvious. The coefficient of Ain1out-star $\left(4.277531^{*}\right)$ indicates that the finance flow in the network operates in a mode of aggregation transfer. In the actor-relation effects, the indicted person's sender effect $(-0.482213)$ is negative and not significant, and the receiver effect $(0.805792 *)$ shows a significant positive effect, indicating that the indicted person is the destination of the finance flow. The coefficient of the interaction $(1.292391 *)$ indicates that the indicted persons are prone to establishing financial relationships with each other, which may explain why they are prosecuted together. The results of the categorical variables fitting show that people in the same community are prone to establishing financial relationships with each other, while it is difficult to establish financial relations within the same level.

Table 5. Exponential random graph model (ERGM) analysis results.

\begin{tabular}{ccccc}
\hline Effects & Estimates & Std. Err. & t-Ratio & Sign. \\
\hline Purely structural effects & & & & \\
arc & -5.961773 & 0.19058 & -0.00001 & $*$ \\
2-in-star & 2.039363 & 0.26784 & -0.04876 & $*$ \\
2-path & 0.27058 & 0.06397 & -0.05768 & $*$ \\
isolates & -2.712007 & 0.34793 & 0.00452 & $*$ \\
AinS(2.00) & 1.967811 & 0.60594 & 0.02872 & $*$ \\
Ain1out-star(2.00) & 2.925775 & 0.87962 & -0.01153 & $*$ \\
Actor-relation effects & & & & \\
indicted_sender & -0.482213 & 0.37923 & 0.10449 & \\
indicted_receiver & 0.805792 & 0.23738 & 0.05713 & $*$ \\
indicted_interaction & 1.292391 & 0.55386 & 0.01906 & $*$ \\
community_matching & 11.645678 & 0.16729 & -0.00087 & $*$ \\
level_matching & -2.396961 & 0.12295 & 0.00001 & $*$ \\
\hline
\end{tabular}

\section{Conclusions and Discussion}

This study used the motif analysis and the ERGMs in social network analysis to analyze the global characteristics of the finance flow relationship network and obtained the microstructural characteristics of the finance flow network and relationships between various factors that affect the formation of the financial flow network.

The research conclusions are as follows: (1) The financial flow network is a sparse network and the financial flows in the organization are not frequent or complicated. (2) The financial flow networks have strong connectivity and the financial relationships cover a wide range. (3) The financial flow network is hidden, and it is not easy to explore the overall outline of the financial flow network. (4) The hierarchical structure of the "5.03" pyramid scheme finance flow network is obvious, and there 
is no cross-community finance flow. (5) The highest level of personnel is at the center of the network and is the end of the flow of finances. The indicted persons are located on the main road of the flow of finances and occupy critical positions. They play a bridge or a core role, which may explain why these people are being sued. (6) The finance flow network presents a pyramid structure. The finances flow from the bottom (edge) of the network to the center. There is no horizontal flow and there is no closed circuit. (7) The network of financial relationships has strong homogeneity. People are more likely to establish financial relationships with people in the same community, and those people who were prosecuted are more likely to establish financial relationships with each other too.

The above conclusions illustrate the finance flow network of the "5.03" pyramid scheme organization from different angles, which is of great significance. The characteristics of the network reflect the hierarchical management, covert operation, aggregated operation, closed transactions, and upper-ranking by shares of the "5.03" pyramid scheme organization, and also reflect the importance, vulnerability, and destructiveness of the finance flow network. These characteristics can help to arouse the vigilance of government departments and improve their coping ability. For example, government departments can use strong connectivity characteristics to carry out detection work. In other words, government departments can excavate the whole organization as long as they find a member in the finance flow network. Government departments can also use the clear and significant characteristics of the finance flow in the network to monitor the organization's funds. These kinds of people and organizations with large inflows of funds, but without clear business support, are easier to be excavated.

In summary, this study expands the comprehension of the pyramid scheme, especially the comprehension of the sustainable development model of the pyramid scheme. However, although the research subject of this paper is a typical South Pyramid Scheme organization and the research framework is objective, there are still some limitations in this work. This paper only studies the structural characteristics of financial flow networks in a specific pyramid scheme organization. The structural characteristics of other types of pyramid scheme organizations are still unclear. In addition, the conclusion of this paper is based on static cross-sectional data, and the structural characteristics of the finance flow network with time series also need to be excavated.

Author Contributions: Conceptualization, P.F.; methodology, D.S., Z.G., and P.F.; resources, P.F.; data curation, P.F.; writing-original draft preparation, P.F. and Z.G.; writing-review and editing, Z.G.; visualization, P.F.; software, P.F.; supervision, Z.G.

Funding: This paper is supported by the National Natural Science Foundation of China (No. 71473263, No. 71571104).

Acknowledgments: The authors would like to thank officer Hui Yu for data support.

Conflicts of Interest: The authors declare no conflicts of interest.

\section{References}

1. Antian Mobile Security Co., Ltd. 2017 China Mobile Pyramid Scheme Fraud Threat Situation Analysis Report; AVLTeam: Beijing, China, 2018.

2. Moisander, J.; Groß, C.; Eräranta, K. Mechanisms of biopower and neoliberal governmentality in precarious work: Mobilizing the dependent self-employed as independent business owners. Hum. Relat. 2018, 71, 375-398. [CrossRef]

3. Koehn, D. Ethical issues connected with multi-level marketing schemes. J. Bus. Ethics 2001, 29, $153-160$. [CrossRef]

4. Jarvis, C. The rise and fall of Albania's pyramid schemes. Financ. Dev. 2000, 37, 46-49.

5. Tencent Security Joint Lab. 2017 Pyramid Scheme Situational Awareness White Paper. Available online: https://slab.qq.com/news/authority/1745.html (accessed on 7 June 2019).

6. Aliber, R.Z.; Kindleberger, C.P. Manias, Panics, and Crashes: A History of Financial Crises; Springer: New York, NY, USA, 2017.

7. Australian Competition and Consumer Commission. Available online: https://www.scamwatch.gov.au/ types-of-scams/jobs-employment/pyramid-schemes (accessed on 7 June 2019). 
8. Bosley, S.; McKeage, K.K. Multilevel marketing diffusion and the risk of pyramid scheme activity: The case of fortune hi-tech marketing in Montana. J. Public Policy Market. 2015, 34, 84-102. [CrossRef]

9. Walsh, J. You Can't Cheat an Honest Man: How Ponzi Schemes and Pyramid Frauds Work and Why They're More Common Than Ever; Silver Lake Publishing: Aberdeen, WA, USA, 1998.

10. Schiffauer, L. Dangerous speculation: The appeal of pyramid schemes in rural Siberia. Focaal 2018, 2018, 58-71. [CrossRef]

11. William, W.K.; Vander Nat, P.J. Multilevel marketing and pyramid schemes in the United States: An historical analysis. J. Hist. Res. Market. 2014, 6, 188-210.

12. Otte, E.; Rousseau, R. Social network analysis: A powerful strategy, also for the information sciences. J. Inf. Sci. 2002, 28, 441-453. [CrossRef]

13. Wasserman, S.; Faust, K. Social Network Analysis: Methods and Applications; Cambridge University Press: Cambridge, UK, 1994.

14. Wellman, B. Network analysis: Some basic principles. Sociol. Theory 2007, 1, 155-200. [CrossRef]

15. Amato, F.; Bosco, A.; Moscato, V.; Picariello, A.; Sperlí, G. A Novel Influence Diffusion Model based on User Generated Content in Online Social Networks. In Proceedings of the International Conference on Data Technologies and Applications, Madrid, Spain, 24-26 July 2017; pp. 314-320.

16. Amato, F.; Castiglione, A.; Moscato, V.; Antonio, P.; Giancarlo, S. Multimedia summarization using social media content. Multimed. Tools Appl. 2018, 77, 17803-17827. [CrossRef]

17. Newman, M.E.J. The Structure and Function of Complex Networks. SIAM Rev. 2003, 45, 167-256. [CrossRef]

18. Shen-Orr, S.S.; Milo, R.; Mangan, S.; Alon, U. Network motifs in the transcriptional regulation network of Escherichia coli. Nat. Genet. 2002, 31, 64-68. [CrossRef]

19. Lusher, D.; Robins, G. Exponential Random Graph Models for Social Networks: Example Exponential Random Graph Model Analysis; Cambridge University Press: Cambridge, UK, 2013.

20. Wang, P.; Sharpe, K.; Robins, G.L.; Pattison, P.E. Exponential random graph (p*) models for affiliation networks. Soc. Netw. 2009, 31, 12-25. [CrossRef]

21. Carlos, L.; Machado, C.; Sarmiento, M. Identifying central bank liquidity super-spreaders in interbank finances networks. J. Financ. Stab. 2018, 35, 75-92.

22. Massimiliano, A.; Pozzolo, A.F. The interbank network across the global financial crisis: Evidence from Italy. J. Bank. Financ. 2017, 80, 90-107.

23. Rednet. Available online: http://hn.rednet.cn/c/2012/08/10/2710452.htm (accessed on 7 June 2019).

24. Coleman, T.F.; Moré, J.J. Estimation of sparse Jacobian matrices and graph coloring problems. SIAM J. Numer. Anal. 1983, 20, 187-209. [CrossRef]

25. Pastor-Satorras, R.; Rubi, M.; Diaz-Guilera, A. Statistical Mechanics of Complex Networks; Springer Science \& Business Media: Berlin/Heidelberg, Germany, 2003; Volume 625.

26. Jonathan, L.G. Graph Theory and Its Applications, 2nd ed.; CRC Press: London, UK, 2005.

27. West, D.B. Introduction to Graph Theory; Prentice Hall: Upper Saddle River, NJ, USA, 1996.

28. Milo, R.; Shen-Orr, S.; Itzkovitz, S.; Kashtan, N.; Chklovskii, D.; Alon, U. Network motifs: Simple building blocks of complex networks. Science 2002, 298, 824-827. [CrossRef]

29. Alon, U. Network motifs: theory and experimental approaches. Nat. Rev. Genet. 2007, 8, 450-461. [CrossRef]

30. Squartini, T.; Garlaschelli, D. Triadic Motifs and Dyadic Self-Organization in the World Trade Network; Springer: New York, NY, USA, 2012; pp. 24-35.

31. Song, N.; Han, H.; Wu, Y. Research on the Model of Stock Market Network and the Purchasing Behavior of Investors. J. Wuhan Univ. Technol. 2013, 35, 257-261.

32. Robins, G.; Pattison, P.; Kalish, Y.; Lusher, D. An introduction to exponential random graph ( $\mathrm{p}^{*}$ ) models for social networks. Soc. Netw. 2007, 29, 173-191. [CrossRef]

33. Snijders, T.A.B.; Pattison, P.E.; Robins, G.L.; Handcock, M.S. New specifications for exponential random graph models. Sociol. Methodol. 2006, 36, 99-153. [CrossRef]

34. Robins, G.; Pattison, P.; Wang, P. Closure, connectivity and degree distributions: Exponential random graph $\left(\mathrm{p}^{*}\right)$ models for directed social networks. Soc. Netw. 2009, 31, 105-117. [CrossRef]

35. Harris, J.K. An Introduction to Exponential Random Graph Modeling; Sage: Thousand Oaks, CA, USA, 2013.

36. Bastian, M.; Heymann, S.; Jacomy, M. Gephi: An open-source software for exploring and manipulating networks. In Proceedings of the Third International on Weblogs and Social Media ICWSM Conference (2009), San Jose, CA, USA, 17-20 May 2009. 
37. Csardi, G.; Nepusz, T. The igraph software package for complex network research. InterJ. Complex Syst. 2006, 1695, 1-9.

38. Handcock, M.S.; Hunter, D.R.; Butts, C.T.; Goodreau, S.M.; Morris, M. Statnet: Software Tools for the representation, visualization, analysis and simulation of network data. J. Stat. Softw. 2008, 24, 1548-7660. [CrossRef]

39. Tran, N.T.L.; Mohan, S.; Xu, Z.; Huang, C.H. Current innovations and future challenges of network motif detection. Brief. Bioinform. 2014, 16, 497-525. [CrossRef]

40. Wernicke, S.; Rasche, F. FANMOD: A tool for fast network motif detection. Bioinformatics 2006, 22, 1152-1153. [CrossRef]

41. Wang, P.; Robins, G.; Pattison, P. PNet: A Program for the Simulation and Estimation of Exponential Random Graph Models; University of Melbourne: Parkville, Australia, 2006.

(C) 2019 by the authors. Licensee MDPI, Basel, Switzerland. This article is an open access article distributed under the terms and conditions of the Creative Commons Attribution (CC BY) license (http://creativecommons.org/licenses/by/4.0/). 